\title{
Emoji usage in brand communication through social media: An evaluation on Turkey context ${ }^{1}$
}

\section{Sosyal medya yoluyla marka iletişiminde emoji kullanımı: Türkiye bağlamına ilişkin bir değerlendirme}

\author{
Fatih Pınarbaşı \\ İbrahim Kırçova ${ }^{3}$
}

${ }^{1}$ This study is derived from PhD thesis of
Fatih Pınarbası, titled "Sensemaking of
Consumers in Digital World" supervised
by Ibrahim Kırcova at Yildız Technical
University.

${ }^{2}$ Research Assistant, İstanbul Medipol University, İstanbul, Turkey fpinarbasi@medipol.edu.tr

ORCID: 0000-0001-9005-0324

3 Prof. Dr., Yıldız Technical University, İstanbul, Turkey, kircova@yildiz.edu.tr

ORCID: 0000-0003-2381-5459

\section{Corresponding Author:}

Fatih Pınarbaşı,

İstanbul Medipol University, İstanbul, Turkey, fpinarbasi@medipol.edu.tr

Submitted: 1/03/2021

Revised: 5/04/2021

Accepted: $12 / 04 / 2021$

Online Published: 25/04/2021

Citation: Pınarbaşı, F., \& Kırcova, İ., Emoji usage in brand communication through social media: An evaluation on Turkey context1, tujom (2021) 6 (1):90-103, doi: https://doi.org/10.30685/tujom.v6i1.109

\begin{abstract}
As one of the crucial elements in today's communication, the emoji concept contains helpful insights about the market environment and brand communication. The research on emoji concept for Turkey context is limited and primarily based on traditional marketing research approaches, and this study aims to provide a data-based approach for understanding the concept by a 25.134 tweets sample from 5 industries/ 25 brands. The first section of the study uses the data retrieved through Twitter API by an exploratory approach that utilizes emoji presence, emoji density, and emoji variety variables. The second stage filters the sample by average interaction amounts and examines the sample by emoji categories and emotions. $21 \%$ emoji intensity and $15 \%$ emoji variety are found for the overall sample, while the smileys \& people category is the most used category in the second stage sample. Top used emojis and emoji sentiment findings are also concluded in the study.
\end{abstract}

Keywords: Emoji, Social Media, Brand Communication, Twitter

Lel Codes: M30, M31

$\ddot{O ̈ z}$

Günümüz iletişiminin önemli bir parçası olan emoji kavramı pazar çevresi ve marka iletişimine dair faydalı bilgiler içermektedir. Türkiye bağlamındaki emoji araştırmaları sınırlıdır ve çoğunlukla geleneksel pazarlama araştırması yaklaşımlarına dayanmaktadır. Bu çalışamda 5 sektör/25 markanın gönderilerinden oluşan 25.134 tweet içeren bir örneklem üzerinden veri merkezli bir yaklaşım kullanılarak emoji kavramı incelenmiştir. Çalışmanın ilk kısmında Twitter API üzerinden edinilen veriler keşifsel bir yaklaşımla incelenip, emoji varlığı, emoji yoğunluğu ve emoji çeşitliliği değişkenler üzerinden yorumlar yapılırken; ikinci kısmında ortalama etkileşim miktarları üzerinden filtrelenme yapılarak, yeni örneklem üzerinden emoji kategorileri ve emoji duygu kategorileri üzerinde değerlendirme yapılmıştır. Çalışmada ilk örneklemde \%21 emoji yoğunluğu, \%15 emoji çeşitliliğine ulaşılırken, ikinci örneklemde en sık kullanılan emoji kategorisi gülücükler ve insanlar kategorisi olarak tespit edilmiştir. Çalışmada ayrıca ikinci örnekleme dair en sık kullanılan emojiler ve emoji kategori bulgularına yer verilmiştir.

Anahtar Kelimeler: Emoji, Sosyal Medya, Marka İletişimi, Twitter

IEL Kodlari: M30, M31 


\section{Introduction}

Emojis are the communication elements that people use for expressing themselves in a graphical approach. They refer to ideograms and smiles, which can be considered the next step of the emoticons (Barbieri et al., 2016). Emojis in communication has emerged as an essential part of the consumers' communication on social media and the web. Huang et al. (2008) conclude that emoticons in communication are related to personal interaction, enjoyment, perceived information richness, perceived usefulness. According to a study by Emojipedia.org (Broni, 2020), tweets containing at least one emoji account for $20.47 \%$ of tweets reviewed in that particular study. The potential of the emoji concept in communication requires new research from various contexts.

There are several studies (Gökaliler \& Saatçioğlu, 2016; Toksöz \& Kahraman, 2017; Kurtoğlu \& Özboluk, 2018; Özdemir et al., 2019) focusing on emoji concept in Turkey context with intention-based or survey approaches; however, studies with the data-centric approach is limited. This study aims to fill this gap by highlighting the emoji concept in social media brand communication and investigating the concept for the industries in Turkey by employing a data-centric approach that uses Twitter tweet data as a sample.

The aim of the study is two-fold; the first aim refers to an assessment of emoji usage in selected industries, and the second aim aims to analyse how emojis can be evaluated with a consumer engagement lens. The first aim is related to an overall examination of the emojis; however, the second aim explores the sample by filtering it with average engagement rates. The study sample consists of 25 brands from 5 industries and refers to 25134 tweets, while the sample for the second part refers to 761 tweets. The methodology for the study is a data-centric approach which consists of retrieving the data by Twitter API and descriptive information by pre-defined categories.

The study starts with a brief overview of emojis concept and social media brand communication, continues with the methodology section, which finalizes with a discussion section. The methodology section consists of two main parts consistent with research aims. The first part evaluates the emoji concept with emoji usage statistics, and the second part evaluates the content (filtered by engagement rates) in terms of top used emojis, emoji categories and sentiments.

\section{Literature review}

\section{Social media and brand communication}

Social media plays a vital role in understanding the market environment with sub-components such as consumers, brands, market environment, as the concept itself is a central issue for marketing research for the industrial and academic side. The social media position by different variables such as the time the consumers and brands spend on, the data which the market produces daily, and the convenience that concept offers for communication between the market actors are the subjects of marketing decisionmaking in recent years.

Brand communication has witnessed many advances in the last decades with the growing popularity of digital platforms and social media, and the "social media and brands" is concluded as one of the themes for social media literature in a review study (Alalwan et al., 2017). From the business side, online textual content could help with insights related to the opinions of consumers related to existing products and services (Mostafa, 2013). For example, Jansen et al. (2009) evaluate and analyze 150.000 microblogging postings in their study, and they conclude that nearly $19 \%$ of the postings have brand mentions included, while the postings with brand mentions contain about $\% 20$ of opinions or sentiments regarding company/service/product. Marketing decision making can use the potential of microblogging platforms or social media platforms for evaluating the market environment.

One of the most powerful platforms for social media communication refers to communication on the Twitter platform. As a text-dominant communication platform, Twitter enables brands to communicate either directly to the audience (one-way announcement) or interactions (with the help of mentions) and conversations regarding specific topics (through \#hashtags). The Twitter environment could help understand the market as the data produced from the market refers to a large amount of size. Liu et al. (2017) employ a topic modelling approach for sample of 1.7 million unique tweets for selected 20 brands (from five industries) while they conclude the relationship between users and brands. The authors 
conclude that the leading topics for interactions of consumers' with brands refer to product, service and promotions. They also conclude the variety of sentiments about brands among the industries and within the industries while pointing out the importance of company-specific analysis of positive and negative tweets. This study focuses on brand communication in the Twitter environment and includes sentiments concept within the selected context of emojis.

The final topic of brand communication on social media refers to the recent advances in social media and digital platforms, as they have various communication elements for marketing decision-making. Emojis are one of the recent phenomenons in social media brand communication, and the concept contains two sides of the consuming; the consumers and the brand.

\section{Emojis and brand-consumer relationship}

Emojis refer to "a standardized set of small pictorial glyphs depicting everything from smiling faces to international flags" (Eisner et al., 2016, 1). Lu et al. (2016) imply that emojis are originated as "compact expressions of emotions". The sophisticated nature underlying the emojis concept can be used either by social media users individually and brands as business communication.

The consumer side of emoji refers to usage motivation, intentions or expressions of individuals. Moussa (2019) evaluates consumers' emotions toward brands in his study and presents an emoji-based metric while concluding its correlation with the American Customer Satisfaction Index for 2017. The usage of emojis for brands in marketing practices is studied in different contexts. Mathews and Lee (2018) evaluate the concept in an exploratory study and conclude that the first objective of using emojis for marketing purpose refers to increasing consumer engagement. According to Das et al. (2019), emoji inclusion in ads is related to higher purchase intention and positive affect. An integrated approach evaluating the emojis concept with consumer and brand sides would contribute to a better understanding of the emojis concept in brand communication.

Emojis have valuable insights for marketing decision making and brand communication, and this study aims to evaluate the concept with a data-centric approach in Turkey and Twitter context. The emojis usage in brand communication, consumer engagement rates for the tweets with emojis and categories \& sentiments for emojis are the subjects of the methodology section.

\section{Methodology}

\section{Data collection and research framework}

The aim of the study refers to the evaluation of emojis usage in brand communication concept in the Turkey market; therefore, the first step of the study focuses on the selection and sampling of the brand accounts on Twitter. It is aimed to investigate the emojis concept by best sampling for the market environment; therefore, rather than focusing on a specific industry or niche, the study focuses on five different industries to evaluate the topic in general. For this purpose, 25 brands (five brands from five industries) are selected from the Social Brands Report (Boomsocial, 2020). The filtering approach is selecting by interaction amounts for excluding specific period-based popularity in general; however, chain stores are preferred rather than individuals brands for the individual brand filtering process. Finally, the Twitter follower count variable is used to rank the brands in the culture \& art and shopping industries. The aim of the study refers to evaluation the brand communication, therefore individual data is not collected for the study as the public accounts of brands are examined in the study. Therefore, it is not in the scope of ethics committee report data collection section. The selected brands and industries are included in Table 1. 
Table 1: Brands / Industries Sample of Study

\begin{tabular}{|c|c|c|c|c|}
\hline $\begin{array}{c}\text { Digital Tv \& } \\
\text { Entertainment }\end{array}$ & Food \& Beverage & Wellness \& Sport & Culture \& Art & Shopping \\
\hline Netflix & Faruk Güllüoğlu & Hillside City Club & İstanbul Modern & Teknosa \\
\hline Blu Tv & KFC Türkiye & $\begin{array}{l}\text { TheLifeCo } \\
\text { Wellbeing }\end{array}$ & $\begin{array}{c}\text { İstanbul Kültür Sanat } \\
\text { Vakfı }\end{array}$ & MediaMarkt Türkiye \\
\hline D-Smart & $\begin{array}{l}\text { Starbucks } \\
\text { Türkiye }\end{array}$ & Sports International & İş Sanat & Gratis \\
\hline $\mathrm{Tv}+$ & $\begin{array}{l}\text { McDonald's } \\
\text { Türkiye }\end{array}$ & Mac Fit & İstanbul Caz Festivali & Hepsiburada \\
\hline S Sport Plus & Terra Pizza & B-Fit & BKM & Migros Türkiye \\
\hline
\end{tabular}

The methodological process of the study consists of four stages; i) data retrieval through Twitter API (Twitter, 2020), ii) descriptive statistics for the overall sample, iii) splitting data by average engagement rates (engagement= retweet + favourite), iv) reporting by emoji and sentiment categories.

The data collection process occurs on 20-21 November 2020, and recent 3200 tweets are fetched for the study through Twitter API (Twitter, 2020). R programming language (R Core Team, 2019) in Rstudio software (RStudio Team, 2020) is employed for the study, and specifically, code package titled "twitteR" (Gentry, 2015) is used to get the data from Twitter API (Twitter, 2020).

Since the Twitter API (Twitter, 2021) allows to retrieve the user postings up to 3200 recent tweets, the query of recent 3200 tweets is employed for data collection. However, the study focuses on the brand posts on Twitter, and retweets and replies are excluded from the sampling; therefore, the sample size for the study consists of 25.134 tweets as a sample. Code package titled "dplyr" (Wickham, François, Henry \& Müller, 2020) and "tidyr" (Wickham, 2020) are used for the data manipulation processes, and the code package titled "emo" (Wickham, François \& McGowan, 2020) is employed for emojis extraction.

The approach side of the methodology consists of two stages, corresponding to the aim of the study. The first part refers to evaluating the overall emojis usage in social media brand communication, while the second part uses consumer engagement for filtering the data. Average values for the engagement rates are calculated, and the content with engagement rates more than averages is used for the second part. The filtered data is used for the detection of top emojis, emojis category and sentiment evaluation. 


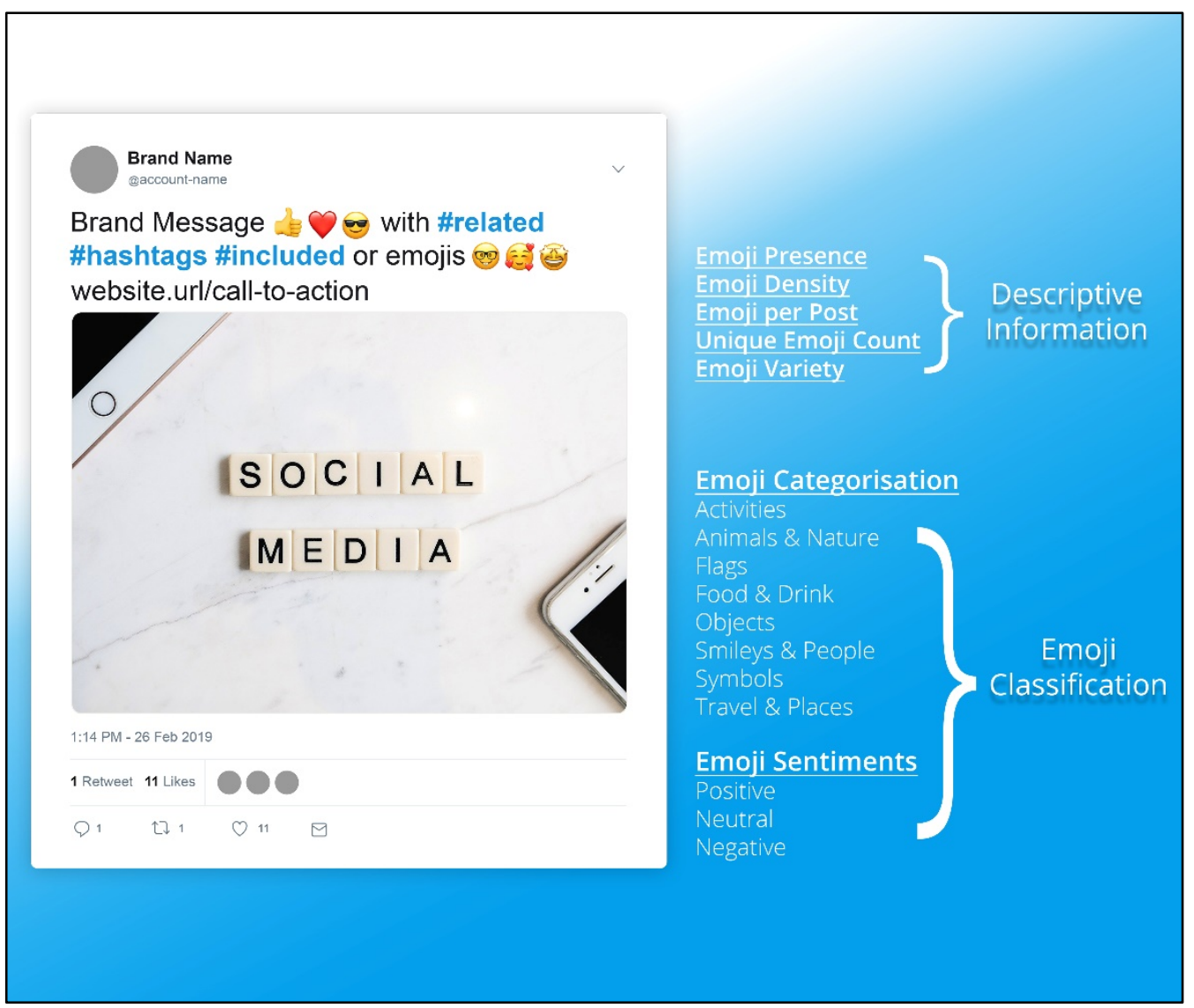

Figure 1: Emoji Research Framework

As Figure 1 points out, a sample Tweet post includes a brand message consists of sample text, hashtags, emojis and website address elements. The first part of the framework refers to descriptive information, and it focuses on the message as a section to evaluate; i) emoji presence, ii) emoji usage density, iii) emoji per Post, iv) unique emoji count, and v) emoji variety. The descriptive information included in this stage provides an overview of the emojis in a brand communication context.

The second part of the framework focuses on the emojis concept and evaluates the emojis by categories and sentiments. Content is filtered by engagement rates (consistent with to study's aim) in this stage, and content and sentiment categorization are employed. The second part simply infers the consumer preference for emojis, as the content used in this stage filtered by engagement rates.

\subsection{Emoji Categories}

Emojis are classified into several categories, and the "emo" (Wickham, François \& McGowan, 2020) code package uses Unicode ${ }^{\circledR}$ Emoji Charts v5.0 classification (Unicode, 2020) for the source of the categories. According to the classification, the main categories for the emojis are; activities, animals \& nature, flags, food \& drink, objects, smileys \& people, symbols and travel \& places.

Table 2: Emoji Category Classification Frequencies

\begin{tabular}{|c|c|c|c|c|c|c|c|c|}
\hline Category & Activities & $\begin{array}{c}\text { Animals \& } \\
\text { Nature }\end{array}$ & Flags & $\begin{array}{c}\text { Food \& } \\
\text { Drink }\end{array}$ & Objects & $\begin{array}{c}\text { Smileys \& } \\
\text { People }\end{array}$ & $\begin{array}{c}\text { Symbols } \\
\text { Travels \& } \\
\text { Places }\end{array}$ \\
\hline $\mathbf{N}$ & 87 & 130 & 271 & 110 & 227 & 2210 & 286 & 249 \\
\hline
\end{tabular}

Source: Unicode® Emoji Charts v5.0, http://unicode.org/emoji/charts/index.html

The main categories for the emojis are grouped into several subcategories such as arts \& crafts, awardmedal, event, game and sports subcategories for the activities main category. The second section of the study focuses on the category/subcategory distribution for the industries. 


\section{Sentiments and emoji}

One of the research fields for the emojis refers to computer science, and sentiment analysis is one of the subfields in computer science (Bai et al., 2019), and according to Liu (2020,1), "sentiment analysis, also called opinion mining, is the field of study that analyzes people's opinions, sentiments, appraisals, attitudes, and emotions toward entities and their attributes expressed in written text.". The approach evaluates the content (generally in forms of text) with specified sub-methods such as lexicon-based or machine learning-based and evaluates the sentiment of the content.

For the methodological approach of sentiment analysis for emojis, this study uses a lexicon-based approach, and the lexicon used in this study is prepared by Brandwatch (2020) research team using DeepMoji (Felbo et al., 2017)'s open API. Positive, negative and neutral emojis are used in this study for classifying emojis in brand communication.

\section{Results}

\section{Descriptive stats}

The first stage of the methodology refers to descriptive stats regarding the total sample of 25134 tweets from 25 brands in 5 industry. Table 3 summarizes the sample size distribution by brands and industries (as total).

Table 3: Sample Size Distribution by Industries and Brands

\begin{tabular}{|c|c|c|c|c|c|}
\hline $\begin{array}{l}\text { Digital Tv \& } \\
\text { Entertainment }\end{array}$ & Netflix & BluTV & D-Smart & $\mathrm{Tv}^{+}$ & S Sport Plus \\
\hline 6389 & 509 & 1084 & 1818 & 501 & 2477 \\
\hline Food \& Beverage & Faruk Güllüoğu & KFC Türkiye & $\begin{array}{l}\text { Starbucks } \\
\text { Türkiye }\end{array}$ & $\begin{array}{l}\text { Mc Donald's } \\
\text { Türkiye }\end{array}$ & Terra Pizza \\
\hline 4345 & 1015 & 709 & 466 & 699 & 1456 \\
\hline Wellness \& Sport & Hillside City Club & $\begin{array}{l}\text { TheLifeCo } \\
\text { Wellbeing }\end{array}$ & $\begin{array}{c}\text { Sports } \\
\text { International }\end{array}$ & Mac Fit & B-Fit \\
\hline 3425 & 1094 & 463 & 592 & 417 & 859 \\
\hline Culture \& Art & İstanbul Modern & $\begin{array}{l}\text { İstanbul Kültür } \\
\text { Sanat Vakfı }\end{array}$ & İş Sanat & $\begin{array}{l}\text { İstanbul Caz } \\
\text { Festivali }\end{array}$ & BKM \\
\hline 3007 & 1932 & 116 & 778 & 156 & 25 \\
\hline Shopping & Teknosa & $\begin{array}{l}\text { MediaMarkt } \\
\text { Türkiye }\end{array}$ & Gratis & Hepsiburada & $\begin{array}{l}\text { Migros } \\
\text { Türkiye }\end{array}$ \\
\hline 7968 & 716 & 1527 & 1027 & 1849 & 2849 \\
\hline
\end{tabular}

Emoji presence -the presence/absence of emoji in the tweet-, emoji intensity -the frequency of tweet with emojis / total tweet-, total emoji count, emoji per tweet, total unique emoji count and emoji variety -total unique emojis / total emoji count- variables are calculated for this stage to evaluate the emojis concept in the social media brand communication. Table 4 shows the descriptive data for the total sample. 
tujom (2021) 6 (1):90-103

Table 4: Descriptive Stats for Emojis Usage in the Sample

\begin{tabular}{lcccccc}
\hline \multicolumn{1}{c}{ Variable } & $\begin{array}{c}\text { Digital Tv \& } \\
\text { Entertainment }\end{array}$ & $\begin{array}{c}\text { Food \& } \\
\text { Beverage }\end{array}$ & $\begin{array}{c}\text { Wellness \& } \\
\text { Sport }\end{array}$ & Culture \& Art & Shopping & $\begin{array}{c}\text { Total } \\
\text { Sample }\end{array}$ \\
\hline $\begin{array}{l}\text { Total Sample } \\
\text { (TS) }\end{array}$ & 6389 & 4345 & 3425 & 3007 & 7968 & 25134 \\
$\begin{array}{l}\text { Sample with } \\
\text { Emoji (SwE) }\end{array}$ & 1092 & 1461 & 906 & 22 & 1847 & 5328 \\
$\begin{array}{l}\text { Emoji } \\
\text { Intensity (SwE }\end{array}$ & $17 \%$ & $33 \%$ & $26 \%$ & $\% 0,7$ & $23 \%$ & $21 \%$ \\
$\begin{array}{l}\text { / TS) } \\
\text { Total Emoji } \\
\text { Count (TEC) }\end{array}$ & 1908 & 2846 & 1812 & 28 & 2517 & 9111 \\
$\begin{array}{l}\text { Emoji per } \\
\text { Tweet }\end{array}$ & 1,74 & 1,94 & 2 & 1,27 & 1,36 \\
$\begin{array}{l}\text { Total Unique } \\
\text { Emoji }\end{array}$ & 327 & 314 & 379 & 14 & 373 & 1,71 \\
Emoji Variety & $17 \%$ & $11 \%$ & $20 \%$ & $50 \%$ & $14 \%$ \\
\hline
\end{tabular}

Table 4 illustrates the study sample in terms of emoji usage, and descriptive information with three variables is included in the table. The first variable -emoji intensity- refers to the amount of sample with emojis in the total sample (by dividing the numbers), and the overall emoji intensity of the sample is $21 \%$, which refers to that one of five tweets includes at least one emoji. The highest emoji intensity refers to food \& beverage and wellness \& sports industries, while the lowest one refers to culture \& art. The second variable -emoji per tweet- refers to the ratio of total emoji count/sample with emojis, while the most significant ratio refers to wellness \& sports industry and food \& beverage and the lowest ratio refers to culture \& art. On the other hand, the overall ratio of emoji per tweet is 1,71 , which means that the sample with emojis uses at least one emoji for each tweet. The final variable - emoji varietyexamines the total unique emojis and total emojis count together and concludes the variety for the emojis concept in brand communication. The overall ratio for emoji variety is $15 \%$, while the most significant industry is culture\&art; however, as the sample of culture art is limited, it refers to an exceptional case. The other most significant ratios refer to wellness \& sport and digital tv \& entertainment industries, while the lowest ratio refers to food \& beverage. The last ratio provides the emojis usage information at a descriptive level.

\section{User engagement stage}

As the study of the aims includes evaluating the brand communication with a user engagement lens, the study sample is filtered through the average engagement rates for the following stages of the methodology. The engagement variables are calculated as the sum of retweet count and favourite count for the content, and the average engagement rates are calculated for each industry. The total sample for the following stages of the methodology refers to 761 Tweets and the details of the sub-samples and average engagement rates as follow; Digital Tv \& Entertainment: 104 Tweets (Avg. Engagement: 713), Food \& Beverage: 176 Tweets (Avg. Engagement: 101), Wellness \& Sport: 320 Tweets (Avg. Engagement: 2,3), Culture \& Art: 8 Tweets (Avg. Engagement: 83), Shopping: 153 Tweets (Avg. Engagement: 170). The culture \& art industry is not excluded in the sample since it shows the absence/low intensity of usage for the emojis concept.

\section{Top used emojis}

The detection of the top used emojis in the methodology contributes to understanding the detail side of emoji usage by user engagement, as the content is filtered in the previous stage of the methodology. Table 5 summarizes the top used emojis for each industry in the engagement sample. The study uses emoji visuals from Emojipedia.org (2020) website. 
Table 5: Top Emojis Used in the Engagement Sample

\begin{tabular}{|c|c|c|c|c|c|c|c|c|c|c|}
\hline \multirow{2}{*}{$\begin{array}{c}\text { Frequency } \\
\text { Rank / } \\
\text { Industry }\end{array}$} & \multicolumn{2}{|c|}{$\begin{array}{c}\text { Digital Tv \& } \\
\text { Entertainment }\end{array}$} & \multicolumn{2}{|c|}{$\begin{array}{c}\text { Food \& } \\
\text { Beverage }\end{array}$} & \multicolumn{2}{|c|}{ Wellness \& Sport } & \multicolumn{2}{|c|}{ Culture \& Art } & \multicolumn{2}{|c|}{ Shopping } \\
\hline & Emoji & Freq. & Emoji & Freq. & Emoji & Freq. & Emoji & Freq. & Emoji & Freq \\
\hline 1 & & $\begin{array}{c}45 \\
(17 \% \\
)\end{array}$ & & $\begin{array}{c}45 \\
(13 \% \\
)\end{array}$ & & $\begin{array}{c}23 \\
(3 \%)\end{array}$ & & $\begin{array}{c}2 \\
(20 \% \\
)\end{array}$ & & $\begin{array}{c}18 \\
(7 \%)\end{array}$ \\
\hline 2 & & $\begin{array}{c}25 \\
(9 \%)\end{array}$ & & $\begin{array}{c}39 \\
(11 \% \\
)\end{array}$ & & $\begin{array}{c}23 \\
(3 \%)\end{array}$ & & $\begin{array}{c}2 \\
(20 \% \\
)\end{array}$ & & $\begin{array}{c}12 \\
(5 \%)\end{array}$ \\
\hline 3 & & $\begin{array}{c}9 \\
(3 \%)\end{array}$ & & $\begin{array}{c}17 \\
(5 \%)\end{array}$ & & $\begin{array}{c}23 \\
(3 \%)\end{array}$ & & $\begin{array}{c}1 \\
(10 \% \\
)\end{array}$ & & $\begin{array}{c}9 \\
(3 \%)\end{array}$ \\
\hline 4 & & $\begin{array}{c}8 \\
(3 \%)\end{array}$ & & $\begin{array}{c}12 \\
(3 \%)\end{array}$ & & $\begin{array}{c}21 \\
(3 \%)\end{array}$ & & $\begin{array}{c}1 \\
(10 \% \\
\end{array}$ & & $\begin{array}{c}8 \\
(3 \%)\end{array}$ \\
\hline 5 & & $\begin{array}{c}7 \\
(2 \%)\end{array}$ & & $\begin{array}{c}11 \\
(3 \%)\end{array}$ & & $\begin{array}{c}16 \\
(2 \%)\end{array}$ & & $\begin{array}{c}1 \\
(10 \%\end{array}$ & & $\begin{array}{c}8 \\
(3 \%)\end{array}$ \\
\hline 6 & & $\begin{array}{c}6 \\
(2 \%)\end{array}$ & & $\begin{array}{c}11 \\
(3 \%)\end{array}$ & & $\begin{array}{c}12 \\
(1 \%)\end{array}$ & & $\begin{array}{c}1 \\
(10 \% \\
)\end{array}$ & & $\begin{array}{c}8 \\
(3 \%)\end{array}$ \\
\hline 7 & & $\begin{array}{c}6 \\
(2 \%)\end{array}$ & & $\begin{array}{c}10 \\
(2 \%)\end{array}$ & & $\begin{array}{c}11 \\
(1 \%)\end{array}$ & & $\begin{array}{c}1 \\
(10 \% \\
)\end{array}$ & & $\begin{array}{c}7 \\
(3 \%)\end{array}$ \\
\hline 8 & & $\begin{array}{c}6 \\
(2 \%)\end{array}$ & & $\begin{array}{c}9 \\
(2 \%)\end{array}$ & & $\begin{array}{c}11 \\
(1 \%)\end{array}$ & & $\begin{array}{c}1 \\
(10 \% \\
)\end{array}$ & & $\begin{array}{c}6 \\
(2 \%)\end{array}$ \\
\hline 9 & & $\begin{array}{c}6 \\
(2 \%)\end{array}$ & & $\begin{array}{c}8 \\
(2 \%)\end{array}$ & & $\begin{array}{c}10 \\
(1 \%)\end{array}$ & & & & $\begin{array}{c}6 \\
(2 \%)\end{array}$ \\
\hline 10 & & $\begin{array}{c}6 \\
(2 \%)\end{array}$ & & $\begin{array}{c}7 \\
(2 \%- \\
2 \%)\end{array}$ & & $\begin{array}{c}10 \\
(1 \%- \\
1 \%)\end{array}$ & & & $\Rightarrow 0$ & $\begin{array}{c}5 \\
(2 \%- \\
2 \%)\end{array}$ \\
\hline
\end{tabular}

Source of Emoji Visuals: http://www.emojipedia.org

Table 5 provides a summary of the top used emojis for the industries included in the study. The table can be interpreted with two approaches; expected emojis for the industries regarding the characteristics of the industry and unexpectable emojis regarding the industries. Emotional-based emojis for the digital tv \& entertainment industry, pizza emoji for the food \& beverage industry, flexed biceps for the wellness \& sports category or the gift box emoji for the shopping industry can be interpreted as expected emojis. However, lion emoji for food \& beverage or tiger emoji for digital tv \& entertainment must be examined in detail for context-based characteristics. For example, the lion emoji could be related to a sponsorship agreement with a football team (with a lion mascot) of a brand titled "Terra Pizza". Further evaluation of emojis could help understand the emojis in brand communication.

\section{Emoji classification results}

The classification stage consists of emoji categories and sentiment categories, and the first stage employs the classification included in the "emo" package (Wickham, François \& McGowan, 2020) (the source of the classification refers to Unicode ${ }^{\circledR}$ Emoji Charts v5.0 classification (Unicode, 2020)). Figure 2-6 show the distribution of content categories for the emojis regarding the user engagement sample. 


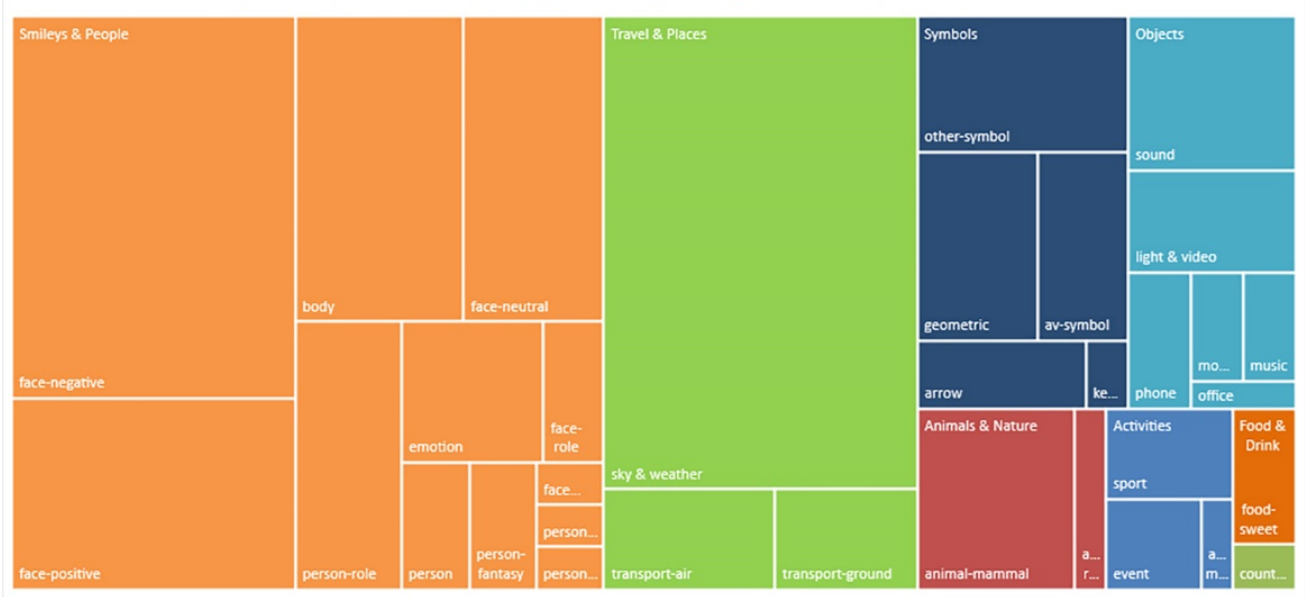

Figure 2: Emoji Category Distribution for Digital Tv \& Entertainment Industry

The majority of the Digital tv \& entertainment industry emojis refer to the Smileys \& people category, while face-negative, face-positive, body, face-neutral are some significant emoji subcategories for that main category. Travel \& places and objects categories follow the lead category for the first industry.

For the rest of the industries, there are two main findings in the distributions of emojis; i) the majority of the emoji categories, and ii) the following categories for each industry.

Industry 2 - Food \& Beverage

| Activities = Animals \& Nature || Flags || Food \& Drink = Objects || Smileys \& People || Symbols || Travel \& Places

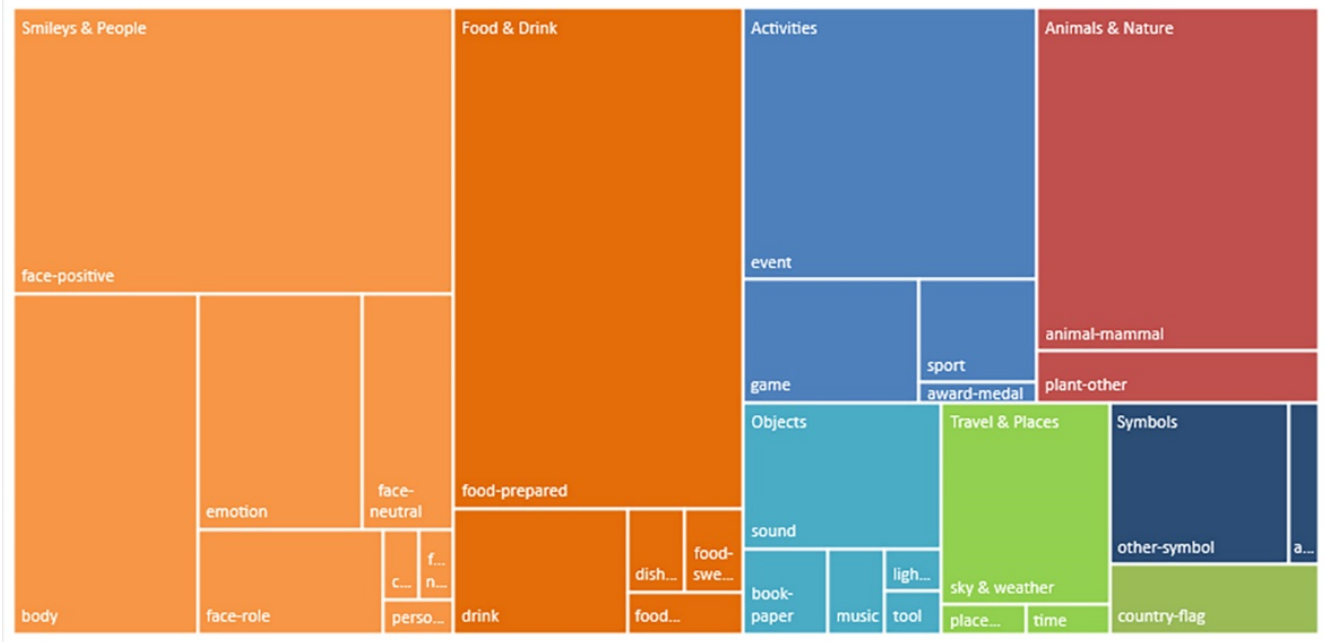

Figure 3: Emoji Category Distribution for Food \& Beverage Industry 
tujom (2021) 6 (1):90-103

Industry 3 - Wellness \& Sport

- Activities = Animals \& Nature = Flags $=$ Food \& Drink $=$ Objects $\mid$ Smileys \& People $\mid$ Symbols $\mid$ Travel \& Places

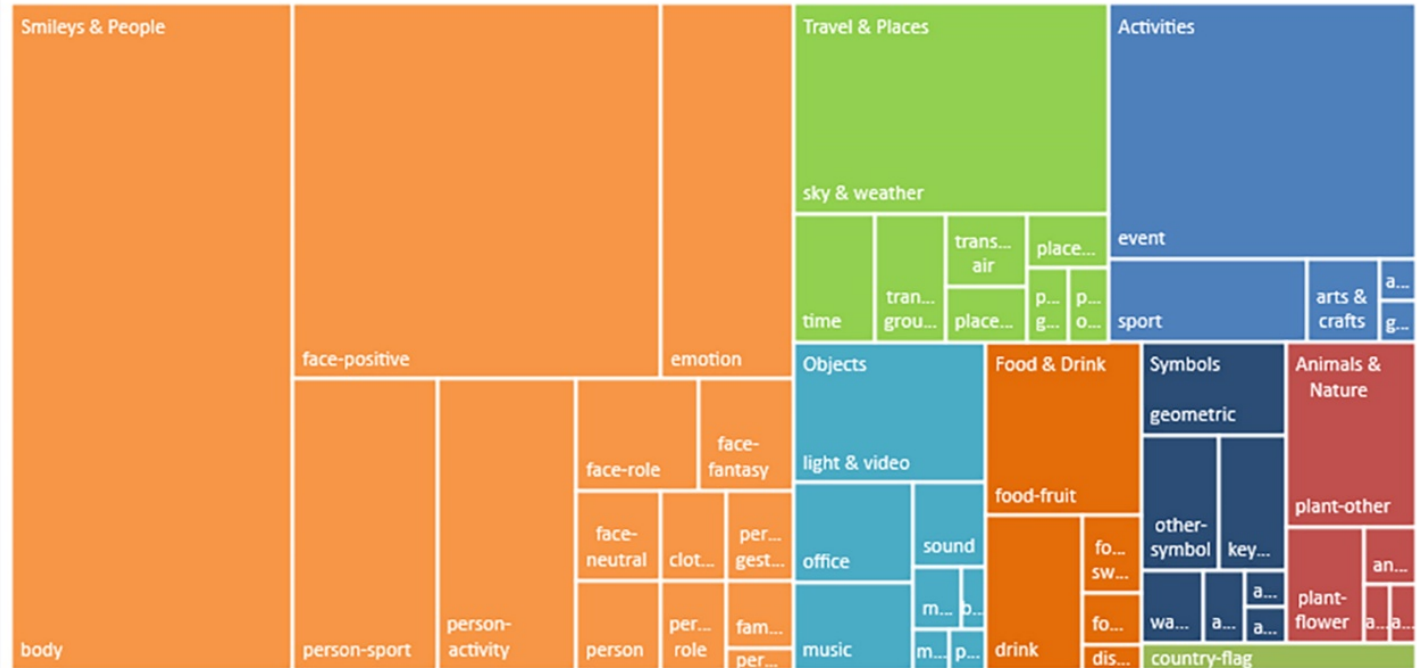

Figure 4: Emoji Category Distribution for Wellness \& Sport Industry

Figure 3 and Figure 4 shows that the food \& beverage and wellness \& sports industry has the smileys \& people types of categories as the most used categories. Further evaluation indicates that the food \& drink category as the second category of the food \& beverage industry, Travel \& Places and Activities categories are the followers for the main category for the Wellness \& Sports industry.

Industry 4 - Culture \& Art

" Activities = Food \& Drink = Objects = Smileys \& People

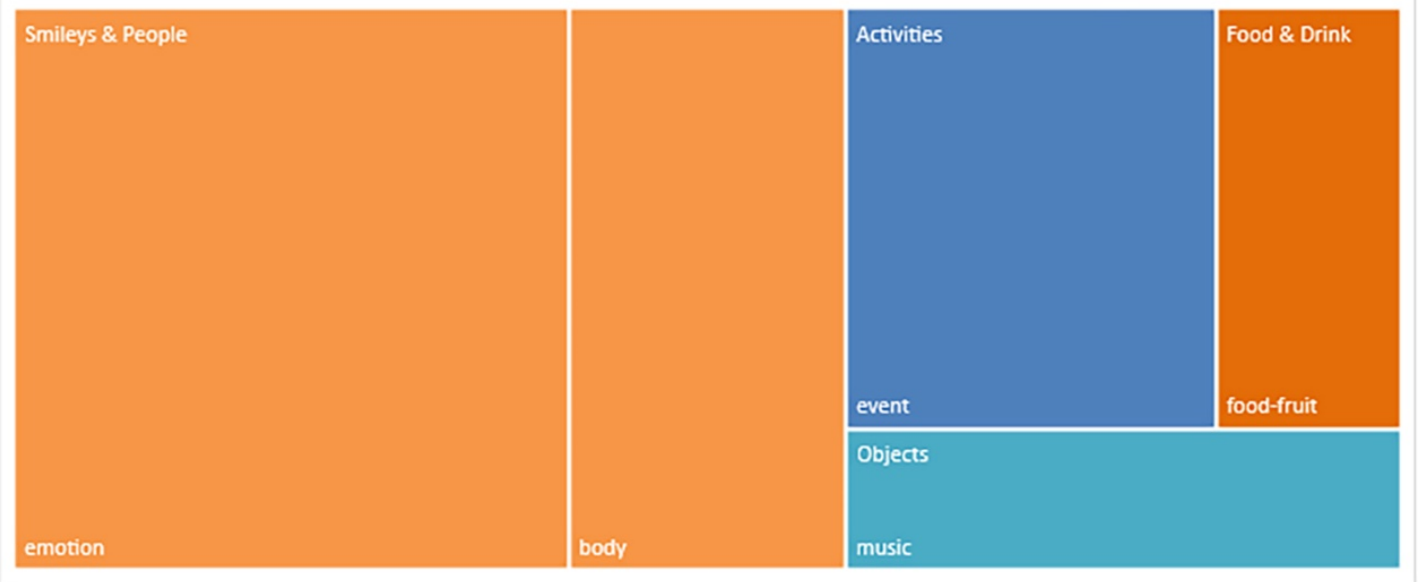

Figure 5: Emoji Category Distribution for Culture \& Art Industry

As the Culture \& Art industry does not include few emojis in the sample, Figure 5 can be interpreted as only a limited view of the emojis included in the sample. 


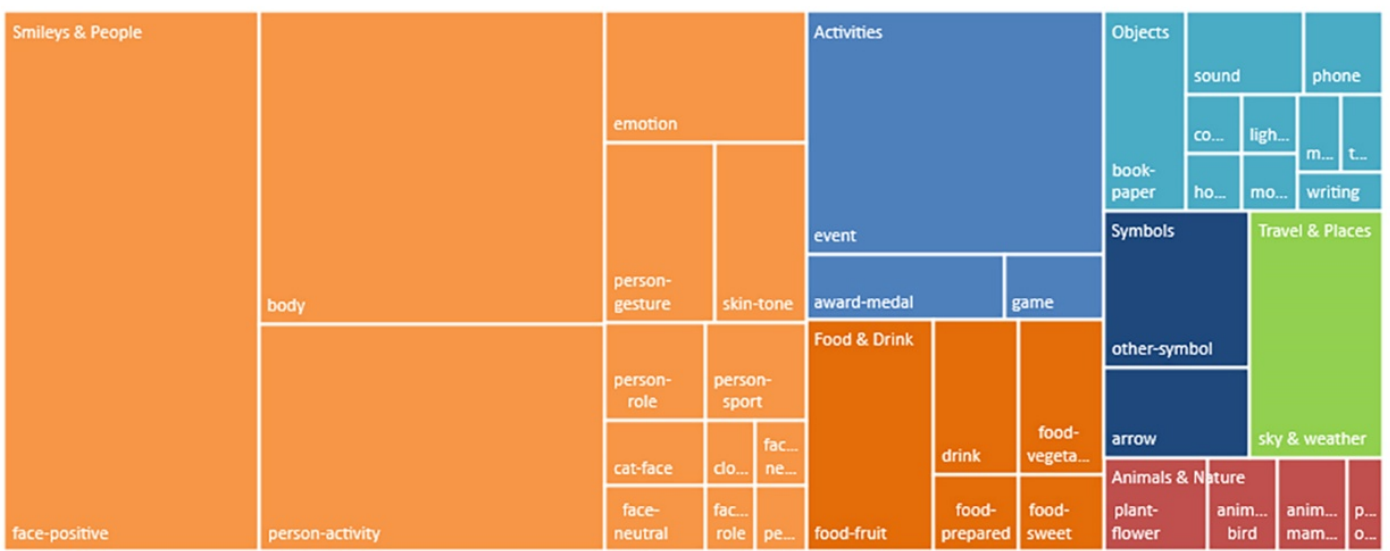

Figure 6: Emoji Category Distribution for Shopping Industry

Finally, Figure 6 shows the category distribution of emojis in the shopping industry. Like in previous industries, smileys \& people category is the first category in the distribution. Activities, objects and food \& drink categories follow the leading category in this industry.

Figure 2-6 provide the general distribution of the emojis categories for the industries. The majority of the emoji categories is concluded as smileys \& people category, and this finding is consistent with the amount of emojis included in this category (see Table 2). On the other hand, the following category/categories for the industries can contribute to understanding social media brand communication through an engagement lens.

\section{Emoji sentiment results}

Following the emoji categories, sentiment analysis is employed by a lexicon-based approach with the help of a lexicon prepared by Brandwatch (2020) research team using DeepMoji (Felbo et al., 2017)'s open API. The study uses three main sentiments (positive, neutral, negative) from the categories included in the lexicon, and Figure 7 shows the distribution of the sentiments.

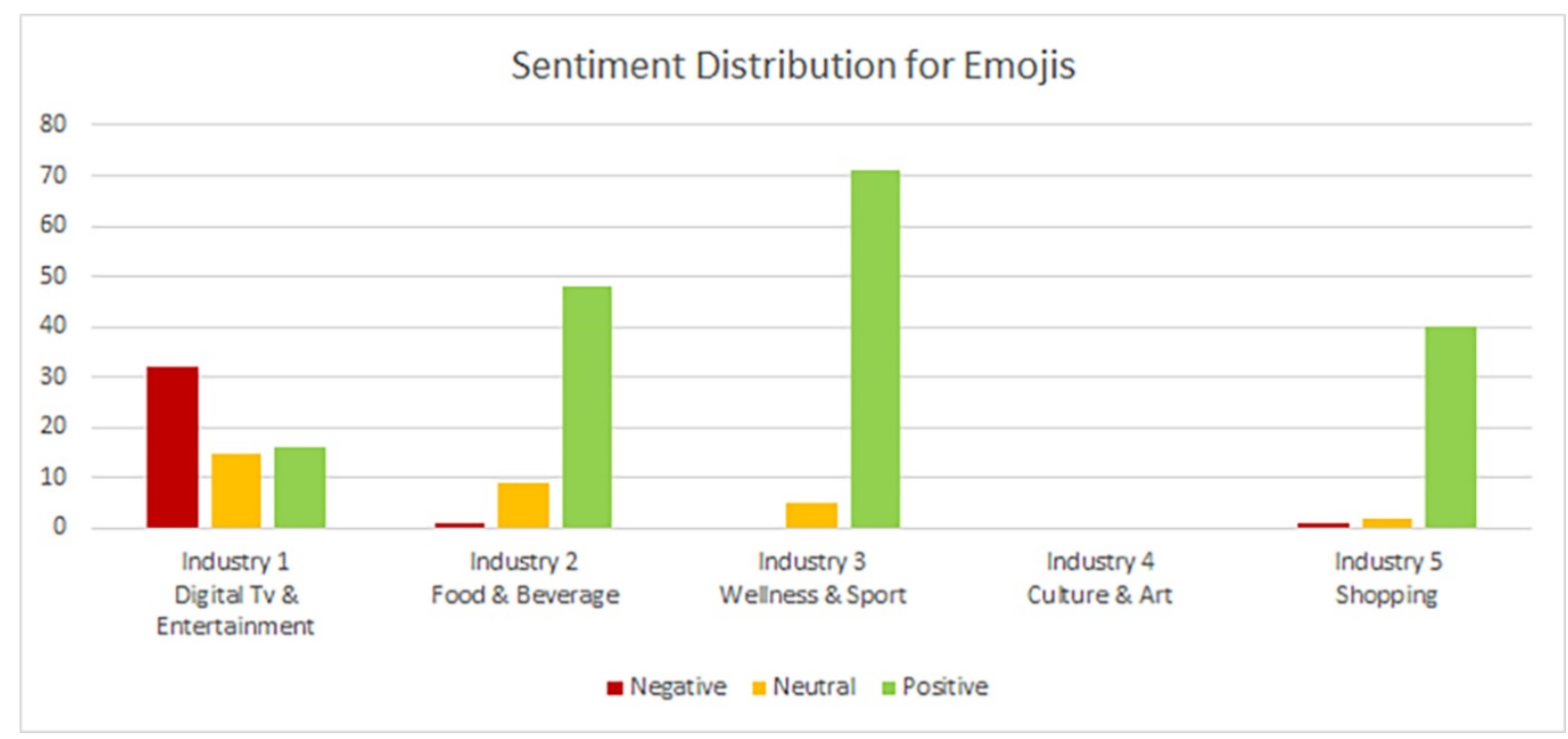

Figure 7: Sentiment Distribution for Emojis

Figure 7 provides an overview of the sentiment distribution for emoji sentiments regarding the industries. The first finding of Figure 7 shows a dominant positive sentiment in the industries titled wellness \& sport, food \& beverage and shopping. On the other hand, the digital tv \& entertainment industry has balanced distribution with neutral, negative and positive sentiments. Finally, the culture $\&$ art industry has not enough data for this figure. 


\section{Discussion}

\section{Conclusion}

The study set out to investigate the emojis concept in social media brand communication with engagement concept, and the emojis concept is evaluated in a two-step approach. The first step evaluates the emojis presence and intensity in the communication, while the second step focuses on the category and sentiments through evaluating the content with filtering by consumer engagement factor. Emoji intensity is calculated as $21 \%$ in the sample (5328 tweets with emojis / 25134 total tweets), and emoji variety is concluded as \%15. These values imply that emojis are employed adequately for communication and can be interpreted as a part of the communication.

The second stage calculates the mean engagement rates for each industry and continues with the tweets, which has more engagement than average values. Total 761 tweets are included in the second step for emoji categorisation and sentiment categorisation. For the emoji content categorisation, "smileys \& people" has the most significant portion of the emojis for all the industries, and the other portions of the categories can differ for each industry. For the sentiment categorisation, positive sentiment emojis stand out for the food \& beverage, wellness \& sport and shopping industries. The digital tv \& entertainment industry has negative values more. However, there are relatively approximate values for all sentiments. Finally, the culture \& art industry has not enough emojis data for summarization.

The study reveals the emojis concept in social media brand communication in an exploratory lens, and the approach study used the concept with its characteristics (emoji categories) and the classification (sentiments). The study's finding will shed new light on the emojis concept for the Turkey context and social media brand communication literature by expanding the concept in selected industries, as the state of emojis in the Turkey context is concluded with a two-level approach.

\section{Theoretical contributions}

The study evaluates the brand communication concept through the sample of brand social media posts from five industries (digital tv \& entertainment, food \& beverage, wellness \& sport, culture \& art, shopping) and 25 brands. It contains emojis concept and consumer engagement together in the Turkey market context. The first contribution refers to a methodology and context-based extension of the literature. Existing studies in the Turkey context literature use survey-based approaches (Gökaliler \& Saatçioğlu, 2016; Toksöz \& Kahraman, 2017; Kurtoglu \& Ozboluk, 2018; Özdemir et al., 2019), and they mostly have a user-centric approach for evaluation of the concept. This study utilizes a brand-based approach for evaluating the concept and employs a data-based methodology for investigation. Five industries / 25 brands sample for Turkey context contributes to emojis concept by contextual extension.

The second contribution refers to conceptual extension by Twitter/social media sample and consumer engagement approach. The study of Bai et al. (2019) reviewing the emoji topic implies communication and marketing as some of the research fields for emoji. This study focuses on marketing communication topics and extends the literature using Twitter as a social media data source. The inclusion of engagement rates employs the consumer side, and the combination of two sides would contribute to the theoretical side of the study by focusing on brand communication and inclusion of user engagement criteria.

\section{Managerial implications}

The study's contribution to marketing decision-making is two-fold; the first part refers to better evaluation of brand communication with the inclusion of the emoji evaluation. The second part refers to the potential of emoji knowledge in different contexts, such as other industries or topics. Marketing decision-making can use the emoji evaluation for;

i) understanding the overall emoji concept in a market,

ii) examination of consumers' reactions to content with/without emoji,

iii) emoji usage density and variety.

These could help marketing decision-makers for communication campaigns in general. On the other hand, there are additional contexts for emojis usage beyond general industries, such as influencer 
marketing, formal/non-formal contexts like banking \& finance. A better understanding of which contexts have different/unexpected characteristics have a knowledge potential for decision-makers.

\section{Limitations and future research}

The limitation of the study refers to selected industries for the sample, as the study aims to explore the emojis concept in brand communication in an exploratory approach. Future studies can focus on extending the scope of the sampling by including different industries and subcontexts.

The methodological approach in the study uses sentiment categories for evaluating the concept in basic level as positive, neutral and negative emojis. However, additional sentiment categories could help future studies by examining sentiments in more detail. Another future research approach is related to the inclusion of culture and country-based differences in international marketing research. Even the same brand is used for the study, the reactions of social media audience in different cultures may differ. Therefore, it is suggested to evaluate the emojis concept in various contexts.

\section{Peer-review:}

Externally peer-reviewed

\section{Conflict of interests:}

The author(s) has (have) no conflict of interest to declare.

\section{Grant Support:}

The authors declared that this study had received no financial support

\section{References}

Alalwan, A. A., Rana, N. P., Dwivedi, Y. K., \& Algharabat, R. (2017). Social media in marketing: A review and analysis of the existing literature. Telematics and Informatics, 34(7), 1177-1190.

Bai, Q., Dan, Q., Mu, Z., \& Yang, M. (2019). A systematic review of emoji: Current research and future perspectives. Frontiers in psychology, 10, 2221.

Barbieri, F., Ronzano, F., \& Saggion, H. (2016). What does this emoji mean? a vector space skip-gram model for twitter emojis. In Calzolari N, Choukri K, Declerck T, et al, editors. Proceedings of the Tenth International Conference on Language Resources and Evaluation (LREC 2016); 2016 May 2328; Portorož, Slovenia. Paris: European Language Resources Association (ELRA); 2016. p. 3967-72.. ELRA (European Language Resources Association).

Boomsocial. (2020). Social Brands Turkey. Retrieved from https://www.boomsocial.com/SocialBrands/2020/Ekim/Twitter

Brandwatch. (2020). The Emoji Report. https://www.brandwatch.com/reports/the-emoji-report/view/

Broni, K. (2020). Emoji Trends That Defined 2020. Emojipedia. https://blog.emojipedia.org/emoji-trendsthat-defined-2020/

Das, G., Wiener, H. J., \& Kareklas, I. (2019). To emoji or not to emoji? Examining the influence of emoji on consumer reactions to advertising. Journal of Business Research, 96, 147-156.

Eisner, B., Rocktäschel, T., Augenstein, I., Bošnjak, M., \& Riedel, S. (2016). emoji2vec: Learning emoji representations from their description. arXiv preprint arXiv:1609.08359.

Emojipedia. (2020). Home of Emoji Meanings. https://emojipedia.org/

Felbo, B., Mislove, A., Søgaard, A., Rahwan, I., \& Lehmann, S. (2017). Using millions of emoji occurrences to learn any-domain representations for detecting sentiment, emotion and sarcasm. arXiv preprint arXiv:1708.00524. 
Gentry, J. (2015). twitteR: R Based Twitter Client. R package version 1.1.9.https://CRAN.Rproject.org/package=twitteR

Gökaliler, E., \& Saatçioğlu, E. (2016). Bir reklam unsuru olarak emoji kullanımı: Emoji içerikli reklamlara yönelik tutum araştırması. Selçuk Üniversitesi Sosyal Bilimler Meslek Yüksekokulu Dergisi, 19(2), 63-91.

Huang, A. H., Yen, D. C., \& Zhang, X. (2008). Exploring the potential effects of emoticons. Information \& Management, 45(7), 466-473.

Jansen, B. J., Zhang, M., Sobel, K., \& Chowdury, A. (2009). Twitter power: Tweets as electronic word of mouth. Journal of the American society for information science and technology, 60(11), 2169-2188.

Kurtoglu, R., \& Ozboluk, T. (2018). Üniversite öğrencilerinin emoji kullanımları ve emoji kullanan markalara karşı tutumları üzerine bir araştırma. Business and Economics Research Journal, 9(3), 697714.

Liu, X., Burns, A. C., \& Hou, Y. (2017). An investigation of brand-related user-generated content on Twitter. Journal of Advertising, 46(2), 236-247.

Liu, B. (2020). Sentiment Analysis: Mining Opinions, Sentiments, and Emotions. Cambridge University Press.

Lu, X., Ai, W., Liu, X., Li, Q., Wang, N., Huang, G., \& Mei, Q. (2016, September). Learning from the ubiquitous language: an empirical analysis of emoji usage of smartphone users. In Proceedings of the 2016 ACM International Joint Conference on Pervasive and Ubiquitous Computing (pp. 770-780).

Mathews, S., \& Lee, S. E. (2018). Use of emoji as a marketing tool: An exploratory content analysis. Fashion, Industry and Education, 16(1), 46-55.

Mostafa, M. M. (2013). More than words: Social networks' text mining for consumer brand sentiments. Expert Systems with Applications, 40(10), 4241-4251.

Moussa, S. (2019). An emoji-based metric for monitoring consumers' emotions toward brands on social media. Marketing Intelligence \& Planning.

Özdemir, G., Gökdağ, R., \& Neslihanoğlu, S. (2019). Sosyal Medyada Emoji Kullanımı ve Anlamlandırılması: Anadolu Üniveristesi İletişim Fakültesi Örneği. Selçuk İletişim, 12(1), 425-443.

R Core Team (2019). R: A language and environment for statistical computing. R Foundation for Statistical Computing, Vienna, Austria. URL https://www.R-project.org/.

RStudio Team (2020). RStudio: Integrated Development for R. RStudio, PBC, Boston, MA URL http://www.rstudio.com/.

Toksöz, L., \& Kahraman, C. (2017). Türk Üniversite Öğrencilerinin Emoji Algısı. HUMANITASUluslararası Sosyal Bilimler Dergisi, 5(9), 247-256.

Twitter. (2020). Twitter API Documentation. Retrieved from https://developer.twitter.com/en/docs/twitter-api

Twitter. (2021). Get Tweet timelines. Retrieved from https:/developer.twitter.com/en/docs/twitterapi/v1/tweets/timelines/api-reference/get-statuses-user_timeline

Unicode. (2020). Unicode® Emoji Charts v5.0. http://unicode.org/emoji/charts/index.htm

Wickham, H. (2020). tidyr: Tidy Messy Data. R package version 1.1.2. https://CRAN.Rproject.org/package=tidyr

Wickham, H., François, R., Henry, L. \& Müller, K. (2020). dplyr: A Grammar of Data Manipulation. R package version 1.0.2. https://CRAN.R-project.org/package=dplyr

Wickham, H., François, R. \& McGowan, L.D. (2020). emo: Easily Insert 'Emoji'. R package version 0.0.0.9000. https://github.com/hadley/emo 